\title{
Physical Property Measurements of Liquid Metals at High Temperatures under Microgravity
}

\author{
Ivan Egry \\ Center for Solidification of Undercooled Melts, ZEUS German Aerospace Center, 51147 Cologne Germany
}

\begin{abstract}
The microgravity environment offers considerable advantages for the measurement of thermophysical properties, in particular for hightemperature metallic melts. The absence of convection and the possibility for containerless processing are the two major benefits. This paper reviews past microgravity experiments dealing with thermophysical property measurements and discusses the methods used. The trend for future microgravity experiments will also be addressed.
\end{abstract}

(Received August 19, 2004; Accepted September 24, 2004)

Keywords: thermophysical properties, containerless processing, liquid metals, microgravity

\section{Introduction}

The measurement of thermophysical properties of the liquid phase, in particular at high temperatures, is a very difficult task under terrestrial conditions. There are two major sources for these difficulties and the subsequent errors: chemical reactions with the container or substrate and the influence of convection.

In this review we shall discuss how the microgravity environment can be used for precise measurement of thermodynamic properties of metallic melts. To take full advantage of the microgravity environment, novel and unconventional techniques have to be developed. In some cases, these measurements are only possible in microgravity, while in others the microgravity environment improves the accuracy considerably. ${ }^{1)}$ The absence of convection is the essential benefit for measurements of transport properties, while containerless processing is the key technology for the study of high-temperature and undercooled melts.

\section{Container Methods}

The methods described in this chapter require a container, generally a crucible. The main reason is that a temperature gradient has to be applied which, in the case of free surfaces, would lead to Marangoni convection, ${ }^{2)}$ thereby destroying the convection-free environment provided by microgravity.

\subsection{Thermal conductivity}

A thermodynamic system tends to maintain spatial homogeneity. Therefore, gradients in intensive variables cause heat or mass flows which try to eliminate these gradients. In linear irreversible thermodynamics, the flows are linearly related to the gradients ${ }^{3)}$ through generalized diffusion (Onsager) coefficients:

$$
\left(\begin{array}{l}
\vec{j}_{c} \\
\vec{j}_{Q}
\end{array}\right)=-\left(\begin{array}{cc}
D & S \\
P & \lambda
\end{array}\right)\left(\begin{array}{c}
\vec{\nabla}_{c} \\
\vec{\nabla} T
\end{array}\right)
$$

If $S$ and $P$ were zero, we would have two independent laws, namely Fick's law: $j_{c}=-D \nabla c$, defining the diffusion constant $D$, and Fourier's law: $j_{Q}=-\lambda \nabla T$, defining the thermal conductivity $\lambda$. The off-diagonal elements are usually very small. The existence of $S \neq 0$ is called Soret effect; it describes thermomigration, i.e. a mass flow caused by a temperature gradient, while $P$ describes a heat flow caused by a concentration gradient.

The main difficulty in performing accurate measurements of diffusion coefficients of liquids is due to the superposition of convective effects. Generally, convection is more effective than diffusion; its presence therefore masks diffusive heat and mass transport. Transient methods have been used quite successfully, based on the fact that the characteristic time for the acceleration of the fluid by buoyancy forces is much longer than the propagation time of the temperature change caused by a strongly localised temperature gradient. Therefore, it is possible by a suitable choice of the experimental conditions and geometrical design of the measuring cells, to perform, in principle, convection-free measurements even on ground. Microgravity experiments can be used to further reduce convection and to extend the convection-free time regime.

The first measurements of the thermal conductivity in microgravity have been performed by Hibiya et al. on InSb. They applied the transient hot-wire method (THW) during a sounding rocket flight, ${ }^{4)}$ and in a drop tower experiment. ${ }^{5)}$ In this method the temperature increase in the wire, generated by a step-function like heat input at time zero, varies linearly with $\ln t$,

$$
\Delta T=\frac{q}{4 \pi \lambda_{\mathrm{ave}}} \ln t+C
$$

where $q$ is the heat input per unit length, $\lambda_{\text {ave }}$ is the average thermal conductivity of the liquid and substrate. The constant slope of $\Delta T$ vs $\ln t$ permits the calculation of the thermal conductivity of the melt. If convection is present, the experimental temperature rise will not vary linearly with $\ln t$, and the calculated apparent thermal conductivity will increase with time, as is shown schematically in Fig. 1. No such time-dependent thermal conductivity was observed in the microgravity experiments.

\subsection{Diffusion}

Like in the case of thermal conductivity, diffusion measurements in microgravity exploit the absence of convection. Whenever there is convection, diffusion meas- 


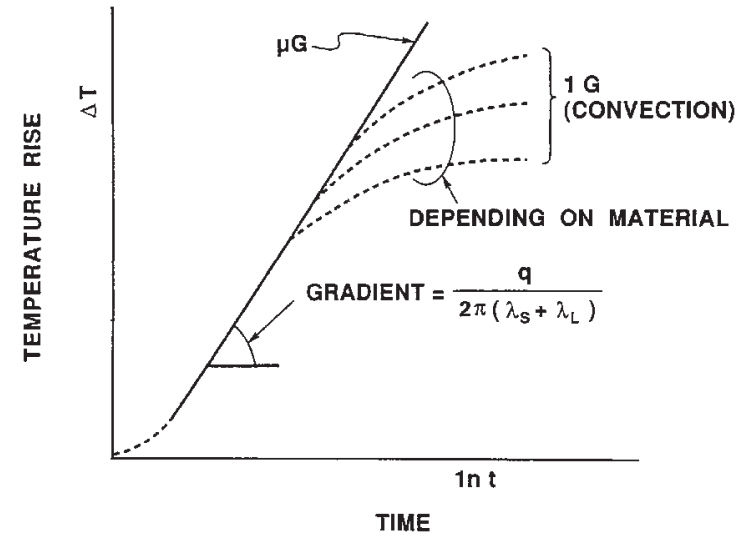

Fig. 1 Influence of convection on thermal conductivity measurements. After Hibiya. ${ }^{4)}$

Table 1 Diffusion measurements by Frohberg and coworkers. First column indicates the mission, the second lists the systems investigated, and the third shows the technique employed.

\begin{tabular}{|c|c|c|}
\hline Mission & System & Technique \\
\hline FSLP & $\operatorname{Sn}(\operatorname{Sn} 112), \operatorname{Sn}(\operatorname{Sn} 124)$ & long capillary \\
\hline \multirow[t]{4}{*}{ D1 } & $\operatorname{Sn}(\operatorname{Sn} 112,124)$ & long capillary \\
\hline & $\mathrm{In}_{85} \mathrm{Sn}_{15} / \mathrm{In}_{75} \mathrm{Sn}_{25}(\mathrm{In} 113, \mathrm{Sn} 124)$ & \\
\hline & $\mathrm{In}_{70} \mathrm{Sn}_{30} / \operatorname{In}_{60} \mathrm{Sn}_{40}(\operatorname{In} 113, \mathrm{Sn} 124)$ & \\
\hline & $\operatorname{In}_{80} \operatorname{Sn}_{20}(\operatorname{In} 113, \operatorname{Sn} 124), \operatorname{In}_{65} \operatorname{Sn}_{35}(\operatorname{In} 113, \operatorname{Sn} 124)$ & \\
\hline \multirow[t]{4}{*}{ D2 } & $\mathrm{Pb}(\mathrm{Pb} 204), \mathrm{Sn}(\mathrm{In}), \mathrm{In}(\mathrm{In} 113), \mathrm{In}(\mathrm{Sn}), \mathrm{Sb}(\mathrm{Sb} 123)$ & long capillary \\
\hline & $\mathrm{In}_{60} \mathrm{Sb}_{40} / \mathrm{In}_{50} \mathrm{Sb}_{50}$ & \\
\hline & $\mathrm{Al} / \mathrm{Al}_{96} \mathrm{In}_{4}, \mathrm{Al} / \mathrm{Al}_{99.6} \mathrm{Bi}_{0.4}$ & \\
\hline & $\mathrm{In}_{90} \mathrm{Al}_{10} / \mathrm{In}_{95} \mathrm{Al}_{5}, \mathrm{Bi}_{90} \mathrm{Al}_{10} / \mathrm{Bi}_{85} \mathrm{Al}_{15}$ & \\
\hline \multirow[t]{5}{*}{ Foton 12} & $\mathrm{In}_{70} \mathrm{Sn}_{30} / \mathrm{In}_{60} \mathrm{Sn}_{40}(\mathrm{In} 113, \mathrm{Sn} 124)$ & shear cell \\
\hline & $\mathrm{Pb}_{95} \mathrm{Ga}_{5}(\mathrm{~Pb} 207, \mathrm{Ga} 71), \mathrm{Pb} / \mathrm{Pb}_{95} \mathrm{Ga}_{5}(\mathrm{~Pb} 207, \mathrm{Ga} 71)$ & \\
\hline & $\mathrm{In} / \mathrm{In}_{98} \mathrm{Al}_{2}, \mathrm{In} / \mathrm{In}_{97} \mathrm{Sb}_{3}$ & \\
\hline & $\mathrm{In}_{95} \mathrm{Sb}_{5} / \mathrm{In}_{87} \mathrm{Sb}_{13}, \mathrm{Sn} / \mathrm{Sn}_{97.5} \operatorname{In}_{1} \mathrm{Bi}_{1.5}$ & \\
\hline & $\mathrm{Al} / \mathrm{Al}_{98.4} \mathrm{Ni}_{1.6}$ & \\
\hline
\end{tabular}

urements are prone to large errors, because convection provides a more effective mass transport than diffusion. Diffusion measurements are carried out in a container, usually a long capillary tube or a shear cell. Microgravity experiments on the self and interdiffusion of different systems were carried out by Frohberg, ${ }^{6-8)}$ Itami and coworkers $^{9,10)}$ and Smith. ${ }^{11-13)}$ The systems investigated by Frohberg during several missions are shown in Table 1. Generally, diffusion coefficients measured in space are 20$40 \%$ lower than the values obtained from terrestrial experiments. The temperature dependence is best described by a power law: $D=K T^{2}$. This is in contradiction to the expected Arrhenius type behaviour, but supports Swalin's fluctuation theory. ${ }^{14)}$ As an example, Frohberg's data on lead are shown in Fig. 2. In addition, Smith found that g-jitter may change the temperature dependence from a square law to a linear dependence. This rather surprising effect still awaits confirmation.

Under microgravity, the Soret coefficient $S$ was determined by Malméjac and coworkers for cobalt in tin by using a shear-cell technique. ${ }^{15)}$ Applying a temperature difference

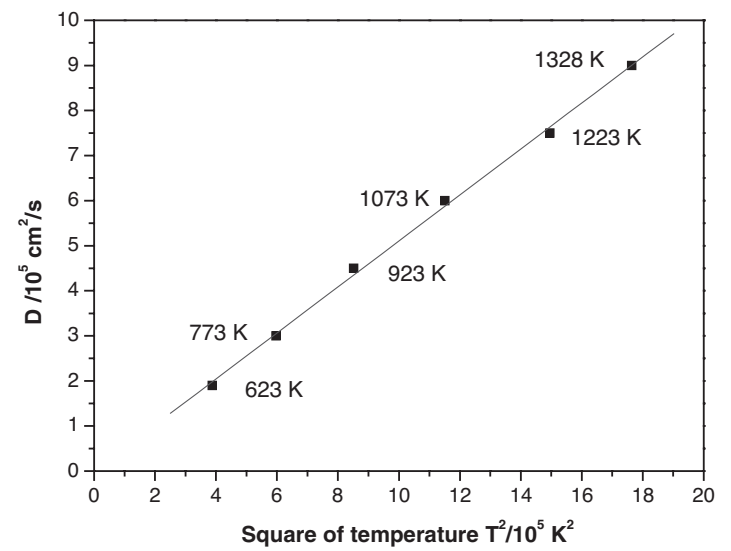

Fig. 2 Self diffusion coefficient of ${ }^{204} \mathrm{~Pb}$, measured during the Spacelab mission D2. After Frohberg. ${ }^{6}$ )

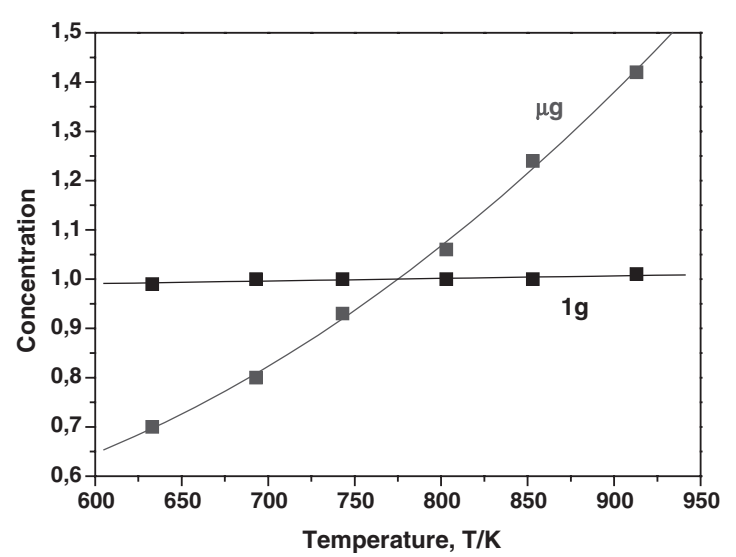

Fig. 3 Soret effect of tin in cobalt at 773 K. After Malméjac. ${ }^{15)}$

of $200 \mathrm{~K} / \mathrm{cm}$, they found a relative concentration difference of nearly $50 \%$, whereas the same experiment performed on ground yielded a homogeneous sample, i.e. $0 \%$ concentration difference. This is shown in Fig. 3.

\section{Containerless Methods}

Thermophysical properties of high temperature, and highly reactive, melts can be conveniently measured by containerless methods, such as electromagnetic levitation. These methods provide the purest environment possible. Since the surface of the liquid sample is not in contact with a wall, Marangoni convection ${ }^{2)}$ will occur, if there is a temperature or concentration gradient along the surface. In addition, the levitation field also induces fluid flow in the melt. ${ }^{16)}$ Therefore containerless techniques are only applicable to those problems where absence of convection is not mandatory. Thermophysical properties of levitated samples have been measured in microgravity during two Spacelab missions, using the electromagnetic levitation facility TEMPUS. ${ }^{17,18)}$

\subsection{Electrical conductivity}

It is possible to measure the electrical conductivity of levitated melts using a non-contact, inductive method. The 
impedance of a coil surrounding the sample is influenced by its electrical conductivity. For spherical samples and homogeneous magnetic fields, as realised in microgravity, this relation is rather simple, ${ }^{19}$ ) whereas under terrestrial conditions, much mathematical and engineering effort must be spent to extract the required information from the measured impedance. ${ }^{20)}$ The complex impedance

$$
Z(\omega, \delta)=U / I
$$

can be determined by measuring amplitudes of current $I$ and voltage $U$, as well as their phase shift. In above equation $\omega$ is the frequency of the levitation field, and $\delta$ is the skin depth, given by

$$
\delta=\sqrt{2 /(\omega \sigma \mu)}
$$

where $\sigma$ is the electrical conductivity, and $\mu$ the magnetic permeability.

By inverting eq. (3), the skin depth can be obtained

$$
\delta=\frac{R_{0}}{2}\left(1-\sqrt{1-\frac{A}{R_{0}^{3}}\left\{\frac{I_{0}}{U_{0}} \cos \varphi-B\right\}}\right)
$$

Here, $R_{0}$ is the radius of the sample, and $A, B$ are two instrument constants. Using eq. (4) yields finally the electrical conductivity $\sigma$. This containerless method allows the extension of measurements into the undercooled liquid state. In this regime, non-linear effects, due to short-range ordering of the liquid phase, can be expected. This was shown to be the case in the binary system $\mathrm{Cu}-\mathrm{Ni}^{2}{ }^{21)} \mathrm{As}$ is evident from eq. (4), the skin depth also depends on the magnetic permeability and is therefore sensitive to magnetic ordering effects. This was demonstrated experimentally on deeply undercooled Co-Pd during the MSL-1 Spacelab mission ${ }^{22)}$ and is shown in Fig. 4. The Curie temperature of the solid phase is around $1250 \mathrm{~K}$, and the steep rise in the apparent electrical resistivity reflects the onset of magnetic ordering. The same behaviour is found for the liquid phase, at approximately the same temperature. This supports the assertion that undercooled liquid $\mathrm{Co}_{80} \mathrm{Pd}_{20}$ becomes a magnetic liquid. ${ }^{23)}$

The electrical conductivity $\sigma$ is of interest in its own, but it also allows to obtain the thermal conductivity $\lambda$ through the

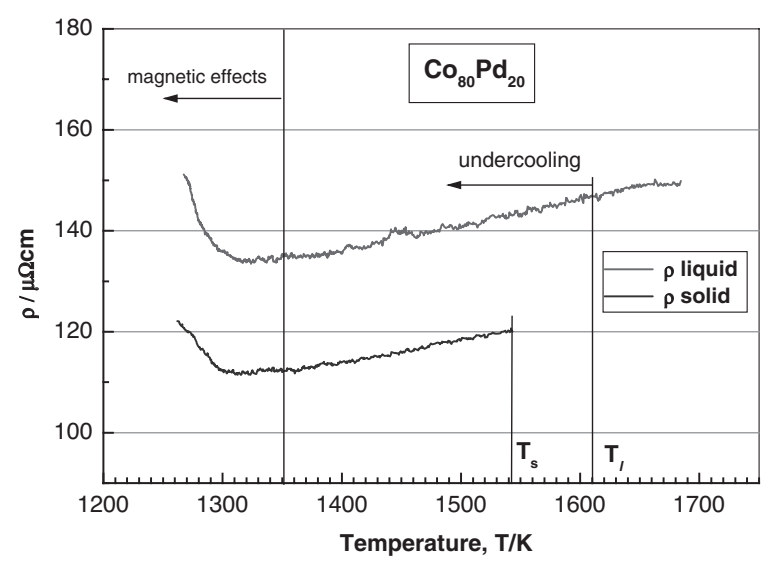

Fig. 4 Apparent electrical resistivity of solid (lower curve) and undercooled liquid (upper curve) $\mathrm{Co}_{80} \mathrm{Pd}_{20}$. The increase below $1300 \mathrm{~K}$ is due to magnetic effects, both in the solid and in the liquid state.
Wiedemann-Franz relation, which is known to hold well for liquid metals. ${ }^{24)}$

$$
\lambda=L \sigma T
$$

Here, $L$ is a universal constant, the so called Lorenznumber, $L=2.44 \mathrm{~W} \Omega / \mathrm{K}^{2}$. Thus, electrical conductivity measurements provide an alternative way to determine the thermal conductivity which is independent of convective effects.

\subsection{Density and thermal expansion}

Density and thermal expansion of levitated drops are determined by recording the visible cross section of the sample. Assuming rotational symmetry, the volume is calculated. Since the mass of the sample is known and does not change, this yields the density. Typically, a resolution of $\Delta V / V=10^{-4}$ is required. This can be achieved using subpixel algorithms for edge detection, curve fitting of the shape, and statistical averaging. ${ }^{25,26)}$

Although such measurements can be performed on ground, ${ }^{25}$ in microgravity the precision of the data is improved and the accessible temperature range is extended. Samwer and coworkers have performed measurements on glass-forming metallic alloys. ${ }^{27)}$ For such systems, two interesting questions need to be addressed: A change in the slope of the density as a function of temperature, i.e. a change in the thermal expansion, in the undercooled regime would indicate a liquid-liquid phase transition, for example phase separation. The other interesting question is related to the glass transition itself: it has been speculated that, at this temperature, the density of the undercooled liquid would become equal to that of the crystalline solid. Unfortunately, the data of Samwer and coworkers cover only a limited temperature range and remain inconclusive. Their data on a $\mathrm{Zr}_{60} \mathrm{Ni}_{9} \mathrm{Cu}_{18} \mathrm{Al}_{10} \mathrm{Co}_{3}$ bulk metallic glass forming alloy is shown in Fig. 5.

\subsection{Specific heat}

A non-contact method developed by Fecht and Johnson ${ }^{28)}$ can be used to determine the specific heat in levitation experiments. It is a variant of non-contact modulation

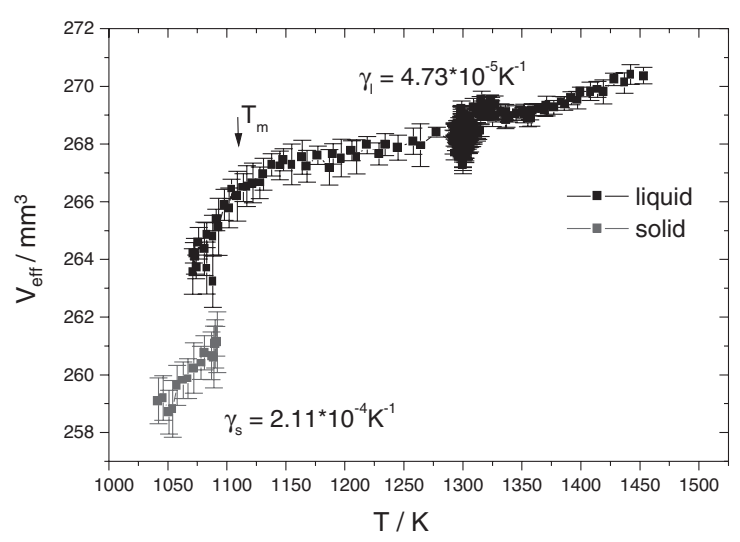

Fig. 5 Molar volume of $\mathrm{Zr}_{60} \mathrm{Ni}_{9} \mathrm{Cu}_{18} \mathrm{Al}_{10} \mathrm{Co}_{3} . T_{\mathrm{m}}$ designates the melting point. The melt has been undercooled by app. $50 \mathrm{~K}$. The volume expansion coefficients $\gamma=1 / V \partial V / \partial T$ are $4.73 \times 10^{-6} \mathrm{~K}^{-1}$ for the liquid and $2.11 \times 10^{-4} \mathrm{~K}^{-1}$ for the solid state. 
calorimetry, normally used in low temperature physics. The heater power is modulated according to $P_{\omega}(t)=\Delta P_{\omega} \cos (\omega t)$ resulting in a modulated temperature response $\Delta T_{\omega}$ of the sample. If heat loss is due to radiation only, i.e., the experiment is performed in vacuo, and if the modulation frequency $\omega$ is chosen appropriately, a simple relation for the the specific heat, $c_{\mathrm{p}}$, can be derived:

$$
c_{\mathrm{p}}=\frac{1}{\omega} \frac{\Delta P_{\omega}}{\Delta T_{\omega}}
$$

These experiments need to be carried out under isothermal conditions, i.e. the sample must be allowed to thermalize at a predefined temperature, before the modulation signal can be applied. Fecht and coworkers ${ }^{29)}$ carried out such experiments during the MSL-1 Spacelab mission. This is shown in Fig. 6, where the quaternary alloy $\mathrm{Zr}_{65} \mathrm{Al}_{7.5} \mathrm{Cu}_{17.5} \mathrm{Ni}_{10}$ was undercooled by $194 \mathrm{~K}$, and modulation calorimetry could be performed in the equilibrium as well as in the undercooled liquid.

Specific heat of this alloy was measured previously close to the glass transition temperrature, but not in the undercooled region below the melting point. For such glassforming systems the question is whether or not the specific heat remains monotonic throughout the undercooled regime, or whether it shows a maximum as function of temperature. The latter would hint to structural changes in the undercooled liquid. The result of Fecht et al. ${ }^{29)}$ support the latter view, as can be seen in Fig. 7.

\subsection{Viscosity and surface tension}

Viscosity and surface tension of levitated samples are conveniently measured by the oscillating drop technique. ${ }^{30)}$ Liquid samples perform oscillations around their equilibrium shape. In microgravity, this is a sphere and in that case, simple formulae can be used to relate frequency $\omega$ and damping $\Gamma$ of the oscillations to surface tension $\gamma$ and viscosity $\eta$, respectively. They read:

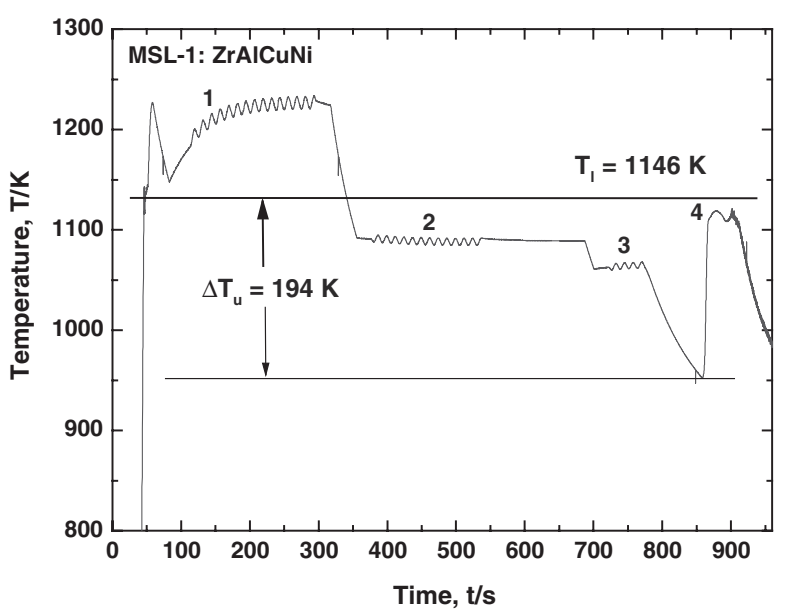

Fig. 6 Modulation calorimetry on ZrAlCuNi alloy during MSL-1 Spacelab mission. The melting temperature of this alloy is $1146 \mathrm{~K}$. Modulation was carried out in the equilibrium liquid (1), as well as in the undercooled liquid (2,3). At point 4, solidification occurs from an undercooling level of $194 \mathrm{~K}$.

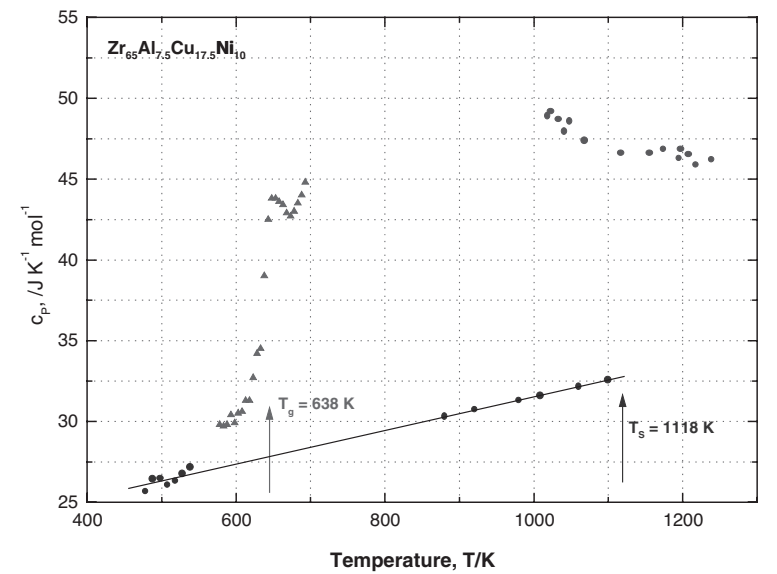

Fig. 7 Specific heat of $\mathrm{Zr}_{65} \mathrm{Al}_{7.5} \mathrm{Cu}_{17.5} \mathrm{Ni}_{10}$. Solid line indicates specific heat of the solid phase, triangles are measurements near the glass transition, circles are results from MSL-1. A non-monotonic behaviour of the specific heat of the undercooled liquid is clearly visible.

$$
\omega^{2}=\frac{32 \pi}{3} \frac{\gamma}{M}
$$

and:

$$
\Gamma=\frac{20 \pi}{3} \frac{R_{0} \eta}{M}
$$

where $M$ is the mass of the droplet and $R_{0}$ its radius. Under terrestrial conditions, the liquid drop is distorted by gravity and the compensating levitation field. As a consequence, the single frequency is split into up to 5 peaks, and all peaks are shifted with respect to eq. (8). A correction formula to account for this effect on the surface tension was developed by Cummings and Blackburn. ${ }^{31)}$

$$
\frac{32 \pi}{3} \frac{\gamma}{m}=\frac{1}{5} \sum_{m} \omega_{2, m}^{2}-1.9 \overline{\Omega_{\mathrm{tr}}^{2}}-0.3\left(\overline{\Omega_{\mathrm{tr}}^{2}}\right)^{-1}\left(g / R_{0}\right)^{2}
$$

Here $\Omega_{\mathrm{tr}}^{2}$ is the mean translational frequency of the drop, and $g$ is the gravitational acceleration.

The sample oscillations are recorded with video cameras. In Fig. 8, oscillation spectra of a gold-copper alloy are shown, recorded on ground and in microgravity. ${ }^{32)}$ As can be seen, both, a splitting of the single frequency into 5 peaks, and a shift to higher frequencies occur. The first effect can be

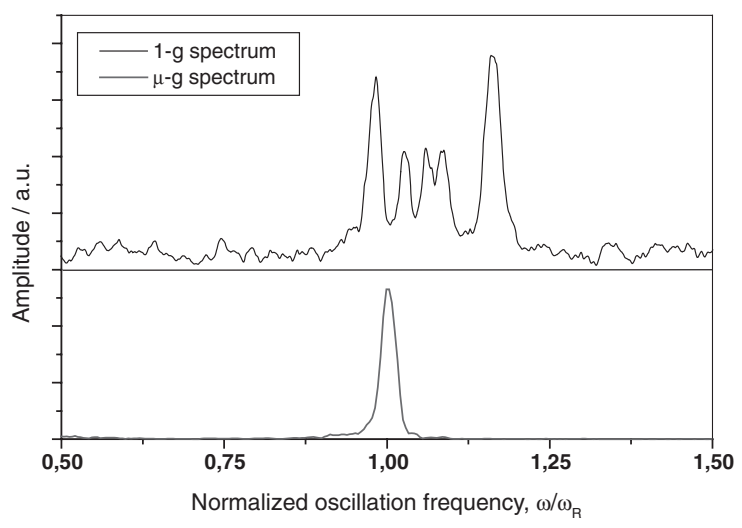

Fig. 8 Frequency spectrum of an oscillating AuCu drop under $1 \mathrm{~g}$ (top) and microgravity (bottom). 


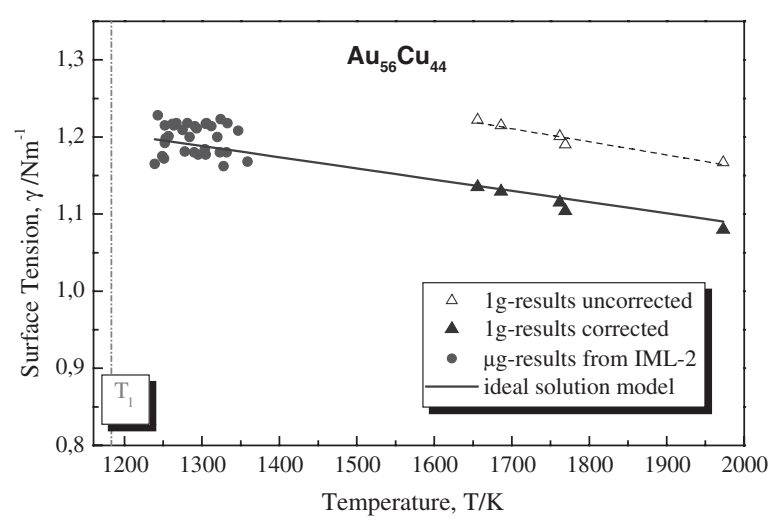

Fig. 9 Surface tension of $\mathrm{Au}_{56} \mathrm{Cu}_{44}$. 1-g results are shown with triangles where open symbols indicate uncorrected data and closed symbols show the corrected value according to eq. (10). Circles represent (uncorrected) microgravity data. Full line shows the prediction of the ideal solution model.

attributed to the breaking of the spherical symmetry, while the latter is due to the magnetic pressure acting on the sample's surface.

By comparing measurements in microgravity with groundbased results, the validity of the Cummings correction could be confirmed experimentally. This is shown in Fig. 9.

Surface tension measurements using the oscillating drop technique are short duration experiments. Nowadays, they are routinely carried out during parabolic flight campaigns. For example, Wunderlich ${ }^{33)}$ has measured the surface tension of a number of industrially relevant multicomponent steels and nickel-based superalloys in the framework of ESA's ThermoLab project.

The oscillating drop technique also allows to measure the viscosity of liquids, by measuring the decay of oscillations and using eq. (9). Since no correction formula, equivalent to the Cummings correction, eq. (10), exist, its application is restricted to microgravity conditions. With this technique, Egry and coworkers ${ }^{34)}$ have measured the viscosity of a $\mathrm{PdCuSi}$ alloy. Their result is shown in Fig. 10 and compared to data by Lee et al. ${ }^{35)}$ Two different datasets are displayed: data during the STS-83 mission were taken with no crew on board Spacelab, while data during STS-94 were recorded

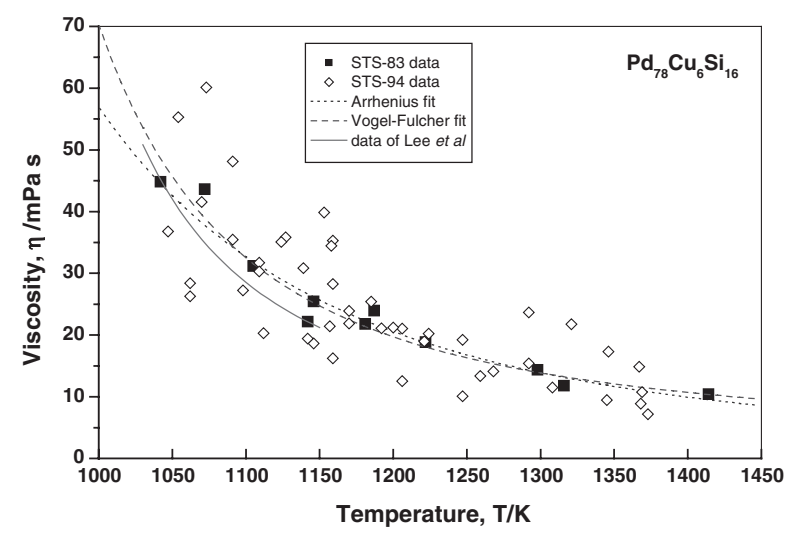

Fig. 10 Viscosity of $\mathrm{Pd}_{76} \mathrm{Cu}_{6} \mathrm{Si}_{18}$ measured during two different Spacelab missions. The data are fitted with an Arrhenius and a Vogel-Fulcher relation, and are compared to previous data by Lee et al. ${ }^{35)}$ during nominal crew operations. Both data yield the same fit, the higher scatter in the STS-94 data is due to g-jitter. Although the data cover a temperature range of $400 \mathrm{~K}$, they are not close enough to the glass transition temperature to distinguish between Arrhenius and Vogel-Fulcher behaviour.

\section{Future Prospects}

Due to the lack of flight opportunities, materials science under microgravity conditions is presently undergoing a difficult transition time. The facilities already operational on board the International Space Station, ISS, among them in particular the Materials Science Glovebox, are of limited use for thermophysical property measurements. Developments for an electromagnetic levitation facility as insert into an Express rack have been abandoned by NASA. The Japan Aerospace Exploration Agency postponed plans for an Electrostatic Levitator for the ISS. JAMIC shot down its drop shaft facility. The second generation TEMPUS facility, MSL-EML, a joint development by ESA and DLR, is still to be built and will not be operational before 2009. During this bridging phase, most thermophysical property measurements are carried out on board parabolic flight within $20 \mathrm{~s}$ of microgravity. This restricts the use of TEMPUS to surface tension measurements, as discussed before. For most other properties, the available microgravity period is not sufficient. Mathiak and coworkers ${ }^{36}$ ) have performed model diffusion experiments in parabolic flights, studying heat diffusion instead of mass diffusion.

As a consequence of lacking flight opportunities, the national space agencies have reconsidered their microgravity related programs. Following the new Space Exploration Initiative, NASA has essentially cancelled its microgravity research program. In contrast, the Canadian Space Agency CSA, the European Space Agency ESA, and the German Space Agency, DLR, have reaffirmed their commitment to microgravity research. In particular, ESA has a strong, application oriented, program with active participation of industrial partners. One such project is ThermoLab, headed by Prof. Fecht, which is entirely devoted to thermophysical measurements of technically relevant multicomponent alloys.

Whereas most thermophysical properties can be measured in a containerless environment using, e.g. MSL-EML, this is not the case for measurements of diffusion and thermal conductivity. For these, dedicated hardware is required, not available presently. In particular, thermal conductivity is an important parameter, which has not been measured in microgravity after the pioneering experiments by Hibiya. There have been plans to develop a laser-flash apparatus for this purpose, but they have never materialized. To the author's opinion, this topic should be taken up again in the future.

When the ISS becomes fully operational, one big bottle neck, namely experiment time in microgravity, will be removed. This is the chance for performing systematic investigations and parametric studies, like, e.g., the dependence of the surface tension on oxygen partial pressure. The challenge lies in the effective use of this precious resource. In the past, microgravity experiments had to work the very first 
time, which unfortunately, but not unexpectedly, was not always the case. It should now become possible to optimize an experiment iteratively, by modifying both, the procedure, and the hardware, just like in ordinary laboratory physics. Generally speaking, however, the emphasis should shift from technology development to exploiting this technology for measurements of industrially and scientifically interesting (multicomponent) alloys.

Although experiment time should be more easily available on the ISS, other resources are not, like crew time, video downlink, mass up- and download. In comparison to other types of experiments, like crystal growth, thermophysical property measurements mainly produce data and do not require download of microgravity processed samples. In addition, one single sample can be used for many different experiments. The limited crew time and real-time video imply that experiments must either become autonomous or must be controlled from ground by telescience tools.

\section{REFERENCES}

1) I. Egry and C. Nieto di Castro, in: Chemical Thermodynamics, T. Letcher ed., (Oxford, Blackwell, 1999).

2) C. Marangoni: Nuovo Cim. 3 (1878) 97-115.

3) S. de Groot and P. Mazur: Non-equilibrium Thermodynamics, (Amsterdam, North-Holland Publ., 1962).

4) S. Nakamura, T. Hibiya, F. Yamamoto and T. Yokota: Int. J. Thermophysics 12 (1991) 783.

5) S. Nakamura and T. Hibiya, in: Proceedings of the 8th European Symposium on Materials and Fluid Sciences in Microgravity, Brussels, ESA-SP-333, 1992, 233.

6) G. Frohberg, in: Scientific Results of the German Spacelab Mission D-2, P. Sahm, M. Keller, B. Schieve eds., (Köln: WPF, 1995).

7) J. P. Praizey, J. P. Garandet, G. Frohberg, A. Griesche and K. H. Kraatz: ESA SP-454 (2000) 481-490.

8) A. Griesche, K. H. Kraatz, G. Frohberg, H. Müller, G. Müller-Vogt, J. P. Garandet, P. Dusserre, J. P. Praizey and G. Mathiak: ESA SP-454 (2000) 985-992.

9) T. Itami, H. Aoki, M. Kaneko, M. Uchida, A. Shisa, S. Amano, O. Odawara, T. Masaki, H. Oda, T. Ooida and S. Yoda: J. Jpn. Soc. Microgravity Appl. 15 (1998) 225.

10) T. Itami, S. Munejiri, T. Masaki, H. Aoki, Y. Ishii, T. Kamiyama, Y. Senda, F. Shimojo and K. Hoshino: Phys. Rev. B 67 (2003) 64201.
11) R.W. Smith: Microgravity Sci. Technol. XI/2 (1998) 78-84.

12) R. W. Smith, X. Zhu, M. C. Tunnicliffe, T. J. N. Smith, L. Misener and J. Adamson: ESA SP-454 (2000) 887-893.

13) R. W. Smith, X. Zhu, M. C. Tunnicliffe, T. J. N. Smith, L. Misener and J. Adamson: Ann. N. Y. Acad. Sci. 974 (2002) 57-67.

14) R. Swalin: Acta Metall. 7 (1959) 736.

15) Y. Malméjac and G. Frohberg, in: Fluid Sciences and Materials Sciences in Space, Walter, H. ed., (Berlin: Springer, 1987).

16) R. Hyers, G. Trapaga and B. Abedian: Met. and Mat. Trans. B 34B (2003) 29-36.

17) T. Tempus, in: Materials and Fluids under low Gravity, L. Ratke, H. Walter, B. Feuerbacher, eds., (Berlin: Springer, 1996).

18) Solidification 1999, W. Hofmeister, J. Rogers, N. Singh, S. Marsh, P. Vorhees, eds., (Warrendale: TMS, 1999).

19) G. Lohöfer and I. Egry, in: Solidification 1999, W. Hofmeister, J. Rogers, N. Singh, S. Marsh, P. Vorhees, eds., (Warrendale: TMS, 1999).

20) T. Richardsen and G. Lohöfer: Int. J. Thermophys. 20 (1999) 1029_ 1039.

21) T. Richardsen, G. Lohöfer and I. Egry: Int. J. Thermophysics 23 (2002) 1207-1216.

22) G. Lohöfer, S. Schneider and I. Egry: Int. J. Thermophysics 22 (2001) 593-603.

23) D. Platzek, C. Notthoff, D. M. Herlach, G. Jacobs, D. Herlach and K. Maier: Appl. Phys. Letts. 65 (1994) 1723-1724.

24) K. Mills, B. Monaghan and B. Keene: Int. Mat. Rev. 41 (1996) 209.

25) E. Gorges, L. Racz, A. Schillings and I. Egry: Int. J. Thermophysics 17 (1996) 1163

26) B. Damaschke, K. Samwer and I. Egry, in: Solidification 1999, W. Hofmeister, J. Rogers, N. Singh, S. Marsh, P. Vorhees, eds., (Warrendale: TMS, 1999)

27) B. Damaschke, D. Oelgeschlaeger, J. Ehrich, E. Dietzsch and K. Samwer: Rev. Sci. Instr. 69 (1998) 2110-2113.

28) H. Fecht and W. Johnson: Rev. Sci. Instr. 62 (1991) 1299.

29) R. Wunderlich, R. Sagel, Ch. Ettel, H.-J. Fecht, D. Lee, S. Glade and W. Johnson, in: Solidification 1999, W. Hofmeister, J. Rogers, N. Singh, S. Marsh, P. Vorhees, eds., (Warrendale: TMS, 1999) 53-64.

30) S. Sauerland, K. Eckler and I. Egry: J. Mat. Sci. Letters 11 (1992) 330.

31) D. Cummings and D. Blackburn: J. Fluid Mech. 224 (1991) 395.

32) I. Egry, G. Lohöfer and G. Jacobs: Phys. Rev. Letts. 75 (1995) 4043.

33) R. Wunderlich and H.-J. Fecht: J. Jpn. Soc. Microgravity Appl. 20 (2003) 192.

34) I. Egry, G. Lohöfer, I. Seyhan, S. Schneider and B. Feuerbacher: Appl. Phys. Lett. 73 (1998) 462-463.

35) S. Lee, K. Tsang and H. Kai: J. Appl. Phys. 70 (1991) 4842.

36) G. Mathiak: Proceedings of the 2nd International Symposium in Physical Sciences in Space, Toronto, 2004, to be published. 